\title{
DESAFIOS E SURPRESAS DA INCLUSÃO DE UMA CRIANÇA CEGA EM
}

\author{
SALA DE AULA
}

\section{CHALLENGES AND SURPRISES OF THE INCLUSION OF A BLIND CHILD IN}

\section{A CLASSROOM}

\begin{abstract}
Valquiria Bertuzzi Veronesi
Mestra em Gestão e Práticas Educacionais pela Universidade Nove de Julho. São Paulo - SP - Brasil valquiriabv@uol.com.br

Francisca Eleodora Santos Severino Doutora em Ciências da Comunicação pela Universidade de São Paulo São Paulo - SP - Brasil frasev@uol.com.br
\end{abstract}

Resumo: Este ensaio retrata a experiência de uma professora que tendo atuado na gestão escolar por doze anos retorna à sala de aula de uma turma de alfabetização com um aluno cego. A proposta tem como objetivos principais promover a reflexão acerca dos desafios e potencialidades decorrentes da inclusão escolar de uma criança cega e contribuir para o desenvolvimento integral dos alunos. Visando alcançar os objetivos, recorreu-se a estudo bibliográfico, rodas de conversas com as crianças, estabelecimento de parcerias e planejamento ressignificado do trabalho para uma aprendizagem ampla e prazerosa. O aporte teórico utilizado perpassa pela legislação e por referências como Freire (1989,1996), Fischer, (1987), Santaella (2012) e Galvão (1995). Como resultados obtidos, destaca-se o estreitamento de vínculo entre todos os envolvidos e as vivências proporcionadas como responsáveis em potencializar possibilidades para novas conquistas e superações. Um cenário de aprendizagem bilateral em que todos foram favorecidos.

Palavras-chave: Educação. Inclusão. Deficiência visual. Arte.

Abstract: This essay portrays the experience of a teacher who has served in school management for twelve years returns to the classroom of a literacy class with a blind student. The main

Cadernos de Pós-graduação, São Paulo, v. 17, n. 2, p. 167-182, jul./dez. 2018. 
objective of the proposal is to promote reflection on the challenges and potentialities resulting from the school inclusion of a blind child and contribute to the integral development of the students. In order to reach the objectives, we used a bibliographic study, a series of conversations with the children, establishing partnerships and re-signification of the work for a wide and pleasant learning. The theoretical contribution used goes through legislation and references such as Freire (1989, 1996), Fischer, (1987), Santaella. (2012) and Galvão (1995). As a result, the link between all those involved and the experiences provided as responsible for potentializing possibilities for new achievements and overcomings is highlighted. A bilateral learning scenario in which all were favored.

Keywords: Education. Inclusion. Visual disability. Art.

017: Ano novo, vida nova, a professora retorna à sala de aula depois de ter
trabalhado 12 anos como gestora na rede pública. Com atribuições diversas, dentre elas gerir e organizar a escola, atender famílias, contribuir com a formação de professores e, claro, sempre com o foco no maior objetivo, ou seja, direcionar todas as ações da escola e dos respectivos envolvidos para a aprendizagem e para o melhor desenvolvimento das crianças.

Mestranda, com pesquisa voltada para os Saberes e faz̧eres dos professores de Educação Infantil em Artes Visuais, inicia 2017 com uma sala de primeiro ano, muito empolgada com essa fase de alfabetização e com a cabeça fervilhando de ideias, pretende colocar em prática tudo aquilo que estudou e contribuiu ao acompanhar professores, nos intensos e produtivos anos anteriores.

Ao chegar à escola e apropriar-se das características dos seus futuros alunos, a professora depara-se com a primeira e grande surpresa: havia entre eles um aluno cego, algo bastante previsível em uma rede inclusiva.

Superada a surpresa, veem as implicações e preocupações das desvantagens que pessoas cegas ou com baixa visão estão em relação às videntes, tendo em vista a predominância de estímulos visuais que nos cercam diariamente. Considerando que, por 
receberem informações ou processarem seus conhecimentos de forma diversa, provocam várias dúvidas e inquietações e dentre elas estão: como organizar as condições educacionais para uma criança desenvolver-se integralmente? De que maneira podem ser asseguradas ações condizentes a uma educação inclusiva?

Para termos uma escola inclusiva há que se atender às necessidades educacionais de cada aluno, dessa forma, a professora busca estratégias e recursos para realizar um trabalho que contemple tanto o aluno cego quanto os demais, proporcionando experiências nas diversas linguagens e com estímulos sensoriais que contribuem significativamente para a aprendizagem de todos, sobretudo do aluno que será denominado JV.

\section{$1 \mathrm{O}$ reencontro com a sala de aula e o desafio da inclusão de uma criança cega}

Segundo Sá, Campos e Silva (2007), a cegueira é "uma alteração grave ou total de uma ou mais funções elementares da visão que afeta de modo irremediável a capacidade de perceber cor, tamanho, distância, forma, posição ou movimento em um campo mais ou menos abrangente." (p. 15). Assim, pode-se ressaltar que, uma vez que a capacidade do sistema visual preservado é responsável por absorver mais de $80 \%$ dos estímulos que estão disponíveis nos ambientes (SÁ, CAMPOS e SILVA, 2007), tanto a pessoa cega quanto a pessoa com baixa visão irá captar uma restrita quantidade de informações advindas do meio ambiente.

Visando atuar de acordo com as políticas educacionais vigentes, o esforço de uma educação inclusiva é bilateral (PONTES, 2008), sendo imprescindível para esse cenário contar com o trabalho coletivo da escola e da família, articulando o trabalho do professor com outros profissionais parceiros (estagiária e especialistas) e os recursos materiais necessários. 
Para garantir o acesso, permanência e qualidade do atendimento e educação à pessoa com deficiência, a Constituição Federal de 1988 (BRASIL, 1988) assegura esse direito a todos em seu Capítulo III, Seção I, artigo 206, bem como a Declaração de Salamanca (1994) garante o atendimento dessas crianças em escolas regulares, cujas práticas são voltadas para elas e suas especificidades.

Diante dessa perspectiva, o município de Santo André adere ao princípio inclusivo desde 1989, atendendo pessoas com deficiências nas salas regulares de ensino. A partir de 1997, ocorre a implantação de uma cultura de "educação inclusiva" para que o trabalho com as crianças, jovens e adultos com deficiências seja ampliado e efetivo. Em 1998, cria-se o Centro de Atenção ao Desenvolvimento Educacional (CADE). Esse serviço da Secretaria de Educação atende a todas as etapas de ensino, desde a Educação Infantil até a Educação de Jovens e adultos, fornecendo acompanhamento e assessoria pedagógica, facilitando o acesso e permanência do aluno com deficiência, que está devidamente matriculado na rede municipal de ensino.

Isto posto, a professora organiza um projeto de ações e práticas pedagógicas, pautadas em princípios que delineiam uma educação integral, visando abarcar a integralidade do ser, conforme esclarece Wallon (In: GALVÃO, 1995, p.29): "O homem é determinado fisiológica e socialmente, sujeito, portanto, a uma dupla história, a de suas disposições internas e a das situações exteriores que encontra ao longo de sua existência". Wallon recorre ao materialismo dialético que contribui para superar os paradoxos que dificultam a compreensão de realidade, a qual se apresenta em constante transformação. Preocupado com a infância, Wallon entende que a escola necessita considerar a criança um ser inteiro, que interage com o meio em que vive, portanto um ser ativo e social.

A sociedade atual, segundo Bauman (2009), não se pauta mais em estágios sólidos, previsíveis, os quais são cunhados pela durabilidade e a lógica. Por conseguinte, 
o trabalho com a diversidade, em uma escola inclusiva, é compatível com essa nossa sociedade contemporânea; que Bauman (2009) retrata pela fluidez, incertezas e imprevisibilidade, as quais conduzirão a novas práticas educacionais tão necessárias à aproximação das relações que se estabelecem entre os conhecimentos e os legítimos sujeitos que a compõem.

Frente ao desafio de buscar um caminho adequado à inclusão de uma criança cega ao grupo de crianças da mesma idade, que cursam a escola básica, a professora segue em frente refletindo sobre a exigência de encontrar referências conceituais, que lhe permitam trabalhar em prol da inclusão e aprendizado qualificado dessa criança; contudo, sem descuidar dos outros alunos, que demandam atenção para a apreensão dos conteúdos curriculares adequados à série que cursam.

Assim sendo, a professora demanda esforços para contemplar e integrar as diversas linguagens, sobretudo as Artes Visuais que possibilitam o exercício da aprendizagem ativa, na qual o aluno é protagonista de seu aprendizado. Nessa proposta, o aluno é levado a apropriar-se de dinâmicas interativas que tem por referência as balizas dialógicas traçadas pela professora. Profissional que, no entanto, respeita o tempo, a criatividade e as escolhas dos alunos. Distanciando-se assim de práticas tradicionais, centradas no adulto, na transmissão e reprodução passiva dos conhecimentos.

A partir de uma nova dinâmica metodológica que pressupõe o reconhecimento do colega cego, todos os alunos e também a professora encontram, com o apoio da Arte aplicada à educação, a mediação necessária para a compreensão dessa condição especial, e, enfim sustentados pela reciprocidade na relação dialógica entre o eu e o outro, seguem encontrando a síntese identitária necessária à aprendizagem.

Processos de criação envolvendo as crianças tornou possível estabelecer um liame entre a professora e seus alunos. Entretanto, este é um momento em que aflora a contradição entre a sua condição humana de não se sentir preparada para o desafio 
do ensino em condição diferenciada, e o ser professora segura de suas ações, que promoverão as condições necessárias para a objetivação da identidade na apreensão dos conteúdos curriculares. Em Freire (1996) ela obtém encorajamento necessário para a superação da zona de conforto inicial.

O meu respeito de professor à pessoa do educando, à sua curiosidade, à sua timidez, que não devo agravar com procedimentos inibidores exige de mim o cultivo da humildade e da tolerância. Como posso respeitar a curiosidade do educando se, carente de humildade e da real compreensão do papel da ignorância na busca do saber, temo revelar o meu desconhecimento? Como ser educador, sobretudo numa perspectiva progressista, sem aprender, com maior ou menor esforço, a conviver com os diferentes? Como ser educador, se não desenvolvo em mim a indispensável amorosidade aos educandos com quem me comprometo e ao próprio processo formador de que sou parte? Não posso desgostar do que faço sob pena de não fazê-lo bem. (p. 74 e 75)

Tendo como objetivo não restringir ou limitar o aluno ainda mais do que a própria cegueira já o faz, os estímulos e as experiências devem caminhar para a quebra de paradigmas, com ousadia e coerência. Dessa forma, a professora planeja seu trabalho tendo como parâmetro as reflexões sobre sua prática; pautada em princípios de uma educação de qualidade, vivenciando as diversas linguagens, valorizando a cultura da infância, a continuidade educativa entre Educação Infantil e Ensino Fundamental, e assegurando o direito de todos ao acesso e construção de conhecimentos.

Barros (2003) reafirma esses princípios: "[...] entendemos que a ausência de uma discussão sobre a apropriação de diferentes linguagens favorece a permanência da desigualdade de acesso ao patrimônio imaterial socialmente produzido". (p.22). A ausência de reflexão sobre a necessidade de inserção de novas abordagens na escola é para esse autor uma estratégia de manutenção do status quo, estratégia de subordinação e inferiorização de segmentos sociais menos favorecidos. Esse padrão de escola desqua- 
lificada é imposto historicamente como um modelo dual de ensino, derivado dos segmentos sociais dominantes, pois são eles que controlam o acesso desigual e combinado ao conhecimento e à riqueza em escala planetária. $\mathrm{O}$ acesso à Arte e à apropriação das possibilidades pedagógicas que ela oferece é concedido, de modo geral, apenas a essas elites. A concepção de uma escolaridade dual impossibilita a exploração da polissemia nos limites do significado, em diferentes linguagens. Barros (2003) ainda esclarece que:

Nesse contexto, inviabiliza-se o acesso da maioria da população às fronteiras do sentido, em linguagens constituídas modernamente nas manifestações de natureza estética filmográfica, videográfica, infográfica somente acessíveis à compreensão como tal pelo tratamento singular de sua especificidade discursiva, para o qual a escola deve cumprir um papel mediador decisivo. (p.22).

Em certos aspectos, a Arte é fundamental na compreensão da realidade em sua concretude e na vida do sujeito em devir social. A Arte no contexto desse devir, em geral ou inserido no espaço escolar, desempenha a privilegiada função de viabilizar a produção de significações que orientam a aprendizagem, seja no âmbito pessoal, seja no âmbito coletivo. Sendo assim, a Arte na compreensão de Fischer (1987, p. 19) “[...] jogando com sombras ou trazendo luzes a arte jamais é uma descrição clínica do real. Sua função concerne sempre ao homem total, capacita o eu a identificar-se com a vida dos outros, capacita-o a incorporar a si, aquilo que não é, mas tem possibilidade de ser”.

Refletindo, pois, sobre a função da Arte como aquela que destina-se a clarear as ideias e incentivar atitudes necessárias, a tornar as crianças capazes de conhecer e transformar o mundo ampliando os seus horizontes, e também os horizontes coletivos, a professora alfabetizadora está convicta que a Arte é necessária à inserção do menino cego no ambiente escolar, haja vista que instigará o menino à reflexão. Ela cria então a estratégia das surpresinhas, trazendo para a sala de aula uma caixinha com alguns objetos que terão a função de instigar a criança, ampliando seus horizontes. 
Preocupada com a alfabetização, uma vez que a turminha inicia o $1^{\circ}$ ano do $1^{\circ}$ ciclo do Ensino fundamental, mas atenta também a alicerçar a necessária e significativa leitura de mundo, antes da leitura das letras e das palavras, conforme nos ensina Freire (1989): "A leitura do mundo precede a leitura da palavra, daí que a posterior leitura desta não possa prescindir da continuidade da leitura daquele. Linguagem e realidade se prendem dinamicamente" (p. 9). A professora sustenta-se nos preceitos de Freire para proporcionar um momento significativo na infância das crianças, trabalhando não somente a leitura, a escrita, os cálculos, mas as vivências com leitura de imagens, produções artísticas, dança, música, literatura e outros encantamentos existentes ao nosso redor, que são permitidos ao imaginário infantil e a quem dele tem fartas memórias.

Com a leitura de imagens, que se apresentam mediadas por obras de Arte, sejam elas da pintura, da literatura ou da fotografia; disponíveis no acervo da escola, na internet e quando possível, em visita a Museus; a professora propõe-se a oferecer oficinas para que os alunos se habituem com a metodologia ativa, que os tornam protagonistas do agir educativo. Essa ideia converge com a concepção de que a aprendizagem não é um processo realizado pelo outro e sim pela mediação crítica do sujeito histórico com o mundo, ou seja, reportando-se à perspectiva de aprendizagem da autonomia, da curiosidade e de força criadora defendida por Freire (1996), quando diz:

É que o processo de aprender, em que historicamente descobrimos que era possível ensinar como tarefa não apenas embutida no aprender, mas perfilada em si, com relação a aprender, é um processo que pode deflagrar no aprendiz uma curiosidade crescente, que pode torná-lo mais e mais criador. O que quero dizer é o seguinte: quanto mais criticamente se exerça a capacidade de aprender tanto mais se constrói e desenvolve o que venho chamando "curiosidade epistemológica", sem a qual não alcançamos o conhecimento cabal do objeto. (p.27)

Por conseguinte, a professora organiza o acolhimento das crianças com brincadeiras que mobilizam os sentidos, como jogos corporais, músicas, histórias interativas, 
caixa surpresa (com elementos a serem sentidos por meio do tato ou olfato), entre outros. As propostas desafiadoras, que incitam a criação e ludicidade envolvendo as crianças, tornaram possível estabelecer um liame entre a professora e seus alunos.

No início, embora JV demonstrasse interesse em participar de tudo, apresentava um comportamento um pouco arredio, impaciente e egocentrado; não respondia quando alguém dirigia-lhe a palavra, não aceitava o toque ou até mesmo a aproximação das pessoas. Com empurrões e gritos: Sai da frente! Espantava qualquer pessoa que estivesse em seu caminho. Mostrava-se também bastante impaciente e intolerante com a presença dos colegas, falando alto e querendo ser o primeiro a todo o momento. Gradativamente, a professora e a estagiária, por meio do diálogo e vivências, mostram-lhe a importância de ser gentil, pedir licença, falar mais baixo e esperar sua vez.

\section{Modos de conceber e trabalhar com uma criança cega: surpresas e alegria para todas as crianças}

As aulas vão transcorrendo em meio à agitação do grupo, às vivências de diferentes linguagens, às conversas e às brincadeiras. Para envolver a todos os alunos, sobretudo JV, a professora faz uso de diferentes estratégias, traz muitos elementos à escola para que JV possa tatear, sentir e experimentar cada centímetro desses diversos materiais oferecidos e trabalhados com eles. Algumas estratégias foram pensadas e preparadas com o propósito da inserção de JV no processo que configura o espaço da sala de aula. Tais estratégias foram denominadas surpresinhas, algumas das quais foram reservadas para aproximá-lo da construção de conceitos complexos para alguém que possui outra maneira de viver e estar nesse mundo.

Elaborar conceitos sobre objetos, sentimentos, aromas, animais, plantas visando auxiliar a aprendizagem de uma pessoa cega não é um desafio fácil. Aproximar 
objetos, tais como: miniaturas ou réplicas para que a pessoa cega possa ter contato e apropriar-se desses conhecimentos que farão sentido para ela é uma tarefa necessária, uma vez que tais objetos se configuram como elementos mediadores na comunicação dialógica entre os sujeitos de aprendizagem. Sendo assim, a professora sempre apresenta objetos para contextualizar o trabalho desenvolvido: animais em miniatura, girassol de plástico, caixas, sementes, alimentos, elementos da natureza, entre outros.

A caixa surpresa, estratégia que causa grande euforia entre as crianças, é passada para todos os alunos tatearem os objetos nela colocados e as crianças vão falando ao ouvido da professora quais são suas hipóteses em relação ao(s) objeto(s) constante(s) na caixa. A partir do momento em que todos tiveram a oportunidade de explorá-la, o segredo é desvelado pela professora ou por quem trouxe a surpresa. Essa estratégia, além de encantar e desafiar as crianças, pois cada uma fica responsável em trazer um objeto surpresa para a descoberta da semana, as crianças desenvolvem a percepção tátil, a imaginação e a oralidade, dentre outras habilidades.

Algo singular nas vivências deste grupo é que, principalmente na atividade da caixa surpresa, as percepções de um aluno que não enxerga e possui um jeito diferente de caracterizar ou entender os objetos, muito diferente das demais crianças, são ouvidas. Um dia, por exemplo, JV disse que um tubo de balas era um objeto que não podia ficar em pé, ou seja, ele percebeu que suas pontas eram arredondadas e não permitiam o apoio desse objeto em uma superfície plana. Esse tipo de observação não é feita costumeiramente pelas crianças videntes, elas vão direto ao ponto, nomeiam o objeto e não ficam verbalizando suas características, arriscam e dizem o que acreditam que seja aquele determinado objeto ou assumem que o desconhecem.

A professora procura adaptar todas as atividades para o aluno, utilizando texturas, saliências que causam grande desafio e autonomia. Utiliza cola quente, carretilha, diferentes tipos de papeis, massinha de modelar, argila, tinta, palito, canudo, barbante, 
tecido e outros materiais para registrar, contar e relacionar. Todas as experiências perpassam por situações concretas para que se possa chegar às representações abstratas. JV é uma criança muito esperta, tem interesse por tudo que é proposto pela professora e vibra dizendo o que gostou de fazer e em que deseja participar.

Para uma criança cega, a localização espacial é algo muito importante, pois facilita o desenvolvimento de sua autonomia, portanto é necessário informar ao aluno o que irão realizar, o que existe no caminho e ao seu redor. É preciso descrever tudo com riqueza de detalhes, visando facilitar seu acesso e sua compreensão.

JV caminha com autonomia pelos espaços escolares, inicialmente, utilizava somente o piso podotátil e o corrimão. Atualmente, já faz uso da bengala e apresenta tamanha segurança que a professora precisa solicitar-lhe que aguarde o grupo, que não fique tão à frente ou até mesmo que não corra.

No parque, a exploração é intensa. Inicialmente, a professora percorreu todos os brinquedos com JV, dando pistas de como utilizá-los com segurança, os quais foram tateados e calculados por JV para captar a altura, as formas, como proceder e suas possibilidades. Certo dia, atreveram-se a uma subida na árvore, mesmo com alguma limitação, a sensação foi bastante prazerosa e desafiadora. Com o passar do tempo, JV diverte-se em companhia dos colegas, perambulando pelos brinquedos preferidos e arriscando algumas manobras mais ousadas. Esses resultados confirmam o que nos ensina Vigotski (1998) a respeito da zona de desenvolvimento proximal: “[...] aquilo que uma criança pode fazer com assistência hoje, ela será capaz de fazer sozinha amanhã.” (p. 113).

Quando a tinta foi utilizada pela primeira vez, JV não aceitou, ficou desconfiado, preferindo utilizar o pincel. Entretanto, bastou familiarizar-se com sua textura, para empolgar-se com a proposta e interessar-se pela exploração de tintas, melecas em 
diferentes papeis, que na maioria das vezes, deflagra sorrisos e gargalhadas, resultados de uma deliciosa sensação de quem faz uma travessura.

Em uma conversa com a professora de educação física a respeito de suas dificuldades com JV, descobre-se que ele apresentava resistência em virar cambalhota. Com isso, a professora, mais uma vez desafiada, convida JV a fazer uma brincadeira que seu pai fazia com ela quando criança, a brincadeira consiste em um adulto girar uma criança entre suas pernas, dando uma cambalhota no ar. A princípio, ele ficou um pouco apreensivo, mas quando a professora fez com que ele percebesse, tateando, os movimentos da brincadeira realizados com outras crianças, ele sentiu-se mais seguro e aceitou o desafio. Podemos constatar que o estreitamento de vínculo favorece a confiança e ao ser oferecida uma nova vivência, obtém-se mais uma superação.

Outro conceito bastante complexo a ser trabalhado com pessoas cegas ou baixa visão é a construção do conceito de cores. Para a elaboração do conceito de cada cor, a professora utiliza uma grande diversidade de recursos com fortes características olfativas, gustativas e táteis, como por exemplo: elementos da natureza (folhas, grama, ervas medicinais) para o conceito do verde; frutas (maracujá, laranja, abacaxi) e outros alimentos e temperos (macarrão, mostarda), para construir o conceito do amarelo; terra, lascas de canela, café, chocolate para construir o conceito do marrom e assim, sucessivamente. Com muito aroma, textura e gostosura conseguem ressignificar esse conteúdo.

Trabalhar leitura de imagem com uma turma que acolhe um aluno cego, a princípio, pode parecer inadequado ou impossível. No entanto, há que se considerar a definição de leitura de imagem, segundo Santaella (2012):

Quando se trata de explicar as formas específicas de representação, de acesso e de conhecimento da realidade que as imagens suscitam, nada impede que as imagens sejam traduzidas na linguagem que utilizamos para nos comunicar, a saber a linguagem verbal (p. 12). 
Na leitura de imagem da obra Os Retirantes, de Cândido Portinari (1903-1962), conforme a prática utilizada pela a professora, as crianças vão descrevendo o que veem para que JV possa se apropriar dos elementos observados e descritos pelas crianças e assim, os alunos passam a captar as imagens, traduzindo-as e comtemplando-as para JV. O grupo ficou muito interessado pela vida de Portinari e a referida obra causou várias sensações nas crianças, no entanto, é JV quem faz reflexões importantes sobre a seca e o sofrimento do povo do sertão. JV verbaliza que lhes faltam água e comida, o que muitas vezes os levam a morte.

O Dicionário Aurélio Online traz várias definições da palavra "cego", dentre elas estão: "que tem visão perturbada", "que tem o raciocínio perturbado", "em que há escuridão", entre outros. Apenas uma delas refere-se a "estar privado da visão ou tê-la de forma reduzida". No entanto, entende-se que dentro dessa condição de escuridão, há um potencial latente que necessita ser despertado constantemente, e por meio da interação e vivência com os colegas, com a estagiária e com a professora, essa condição é reinventada, conduzindo JV a novos caminhos, ampliando possibilidades.

A relevância desse trabalho sócio-interativo é irrefutável para o pleno desenvolvimento e aprendizagem do aluno, no entanto, Bruno (1997) salienta o quão notável é também para o crescimento profissional da professora e de todos os envolvidos. Com a dinâmica de troca de saberes entre família, escola, professora, estagiária e crianças, no envolvimento ao processo educacional, potencializa os pensamentos para uma responsabilidade coletiva no ensino e aprendizagem de todos, inclusive para uma escola inclusiva.

\section{Algumas considerações}


Por meio da observação e conversas com o aluno e com a estagiária, a professora vai balizando suas práticas e reinventando novas propostas, para que JV e toda a turma adquiram mais segurança e ampliem seus conhecimentos.

Com a confiança entre todos assegurada, especialmente a de JV, a professora consegue adentrar seus pensamentos, que outrora ficavam guardados, em segredo. Com isso, vez ou outra, JV dispara, durante as conversas, o que não conhece, o que não sabe, quais experiências nunca teve e assim a professora vai "coletando" esses dados para que possa planejar suas aulas e contemplar suas necessidades, trazendo materiais novos e diversificados, objetos que JV possa sentir seu aroma, tocar ou até mesmo degustar. Ele também verbaliza seus desejos que são possíveis de realizar, como ter uma bola de guizo, fazer bolinhas de sabão e correr sem parar.

Ao longo desse primeiro semestre, percebem-se nitidamente as conquistas não só de JV, mas de todo o grupo: alunos, estagiária e professora. Cenário auspicioso, em que todos são privilegiados. Aprendendo uns com os outros, num diálogo constante, ocorre o crescimento pessoal de cada um e profissional, por parte da estagiária e da professora, que trocam constantemente suas angústias e acertos.

Durante esses prazerosos momentos, todos os envolvidos representam, de alguma forma, uma conexão entre a realidade e a compreensão que JV elabora acerca do mundo. Isso contribui para que ele e as demais crianças tenham um período de infância repleto de saberes, vivências e desafios, ou seja, de memórias que lhes serão significativas por toda a vida. 


\section{Referências}

BARROS, Armando Martins de. Práticas discursivas ao olhar: notas sobre a vidência e a cegueira na formação do Pedagogo. RJ: E-Papers Serviços Editoriais, 2003.

BAUMAN, Zygmunt. Os desafios da educação: aprender a caminhar sobre areias movediças. Cadernos de Pesquisa, v. 39, n. 127, maio/ago., 2009.

BRASIL. Constituição (1988). Constituição da República Federativa do Brasil. Brasília, DF: Senado Federal, 1988.

BRUNO, Marilda M.G. Deficiência Visual - Reflexão sobre a Prática Pedagógica. São Paulo: Laramara, 1997. Disponível em: < http://www.deficienciavisual.pt/txt-reflexao pratica pedagogica-Marilda Bruno.htm $>$. Acesso em: 13 set. 2017.

DECLARAÇÃO DE SALAMANCA. Sobre Princípios, Políticas e Práticas na Área das Necessidades Educativas Especiais, Unesco, 1994. Disponível em: < http://unesdoc. unesco.org/images /0013/ 001393/139394por.pdf>Acesso em: 28 jul. 2017.

FREIRE, Paulo. A importância do ato de ler: em três artigos que se completam. São Paulo, Autores Associados: Cortez, 1989.

FREIRE, Paulo. Pedagogia da autonomia: saberes necessários à prática educativa. São Paulo: Paz e Terra, 1996.

FISCHER, Ernest. A necessidade da arte.9. Rio de Janeiro, ed. LTC. 1987.

GALVÃO, Izabel. Henri Wallon: uma concepção dialética do desenvolvimento infantil. Petrópolis, RJ: Vozes, 1995.

PONTES, Patricia A. G. Criança e adolescente com deficiência: impossibilidade de opção pela sua educação exclusivamente no atendimento educacional especializado. In: Inclusão: Revista da Educação Especial. Secretaria de Educação Especial. v. 4, n.1, p.4148, jan/jun 2018. Brasília: Secretaria de Educação Especial/MEC. Disponível em: <http:/portal.mec. gov.br/seesp/arquivos/pdf/revinclusao5.pdf>. Acesso em: 15 set. 2017.

SANTAELLA, Lucia. Leitura de imagens. São Paulo: Editora Melhoramentos, 2012. 
SÁ, Elizabet D. de; CAMPOS, Izilda M. de; SILVA Myriam B. C. Atendimento Educacional Especializado: deficiência visual. SEESP/SEED/MEC Brasília/DF, 2007. Disponível em: <http://portal.mec.gov.br/seesp/arquivos/pdf/aee_dv.pdf>. Acesso em: 13 set. 2017.

VIGOTSKI, Lev S. A formação social da mente: o desenvolvimento dos processos psicológicos superiores. São Paulo: Martins Fontes, 1998.

recebido em 21 ago. 2017 / aprovado em 12 fev. 2018

\section{Para referenciar este texto:}

VERONESI, V. B.; SEVERINO, F. E. S. Desafios e surpresas da inclusão de uma criança cega em sala de aula. Cadernos de Pós-graduação, São Paulo, v. 17, n.2, p. 167-182, jul./dez. 2018. Disponível em: < https://doi.org/10.5585/cpg.v17n2.7733>. 